\title{
Coordination of health care in the Nordic countries
}

\author{
TOR IVERSEN ${ }^{1, *}$ \\ ANDERS ANELL ${ }^{2}$ \\ UNTO HÄKKINEN $^{3}$ \\ CHRISTIAN KRONBORG ${ }^{4}$ \\ THORHILDUR ÓLAFSDÓTTIR ${ }^{5}$
}

\footnotetext{
${ }^{1}$ Department of Health Management and Health Economics, University of Oslo, Norway

${ }^{2}$ Department of Business Administration, Lund University, Sweden

${ }^{3}$ Centre for Health and Social Economics, National Institute for Health and Welfare, Helsinki, Finland

${ }^{4}$ Centre of Health Economics Research, University of Southern Denmark

${ }^{5}$ Department of Economics, University of Iceland
}

\begin{abstract}
Coordination of health care exists at many different levels and in many different forms. We describe the similarities and differences in coordination mechanisms among the Nordic countries. In some respects, the Nordic countries approach coordination problems in similar ways although differences exist. The overall pattern shows that Finland and Sweden have less country-wide coordination compared with the other countries. There are many questions and few answers with regard to which mechanisms work best. Hence, coordination mechanisms in health care seem to be an important area for further research. We outline a few topics for future joint Nordic research in this area.
\end{abstract}

JEL classification: I11, I18

Key words: health care, regulation, coordination, Nordic countries

\section{Introduction}

Health care systems face many coordination problems. These problems are often handled differently in different countries. Important examples include how to allocate activities among a set of public hospitals, how to coordinate health care interventions for a person with diabetes or other chronic conditions, how to coordinate the activities of various clinics within a hospital or between primary and secondary care and how to allocate or allow patients to choose among various sorts of providers. Mechanisms for coordination include the market in a broad sense, regulations, hierarchies/organizations, networks, etc. Within these categories mechanisms can be designed in many different ways.

In this paper we study coordination of health care from a system or governance perspective, rather than a micro-management perspective. The main contribution of the paper is to provide an overview of the coordination mechanisms used within the health care systems in the Nordic countries. This investigation is important, as the literature on coordination mechanisms suggests that the appropriateness of each particular coordination mechanism is context specific. That is, what works well in one system does not necessarily work well in a setting with different system characteristics.

* Correspondence to: Tor Iversen, Department of Health Management and Health Economics, University of Oslo, Postboks 1089, 0318 Oslo, Norway. E-mail: tor.iversen@medisin.uio.no

dx.doi.org/10.5617/njhe. 2846 
A second contribution of the paper is to identify research opportunities to address the question of whether some types of coordination mechanisms are more appropriate in Nordic health care systems than others. Our approach creates an opportunity to address the methodological problem of national studies of not being able to establish exogenous variation in the institutional variables within a country. With data from several of the Nordic countries, it is easier to compare treatment and control countries when some fundamental features are stable across countries.

We focus on several important areas of coordination: At the system level, we describe 1) coordination across hospitals and how that is handled in the Nordic countries, and 2), coordination between general practitioner (GP) services and specialist care. At the level of individual patients, we explore 3 ) how medical care to cancer patients is coordinated in the Nordic countries, 4) how coordination of health care to patients with diabetes type 2 is handled, and finally, 5) coordination of long term care and medical care to the elderly.

The paper is organized as follows. Section 2 briefly discusses types of coordination mechanisms in health care. Section 3 describes coordination mechanisms for some important parts of the Nordic health systems. Section 4 provides a summary. Section 5 describes benefits and costs of the coordination mechanisms as described in the international research literature. Section 6 concludes with suggestions regarding topics for future Nordic comparative research.

\section{Types of coordination mechanisms in health care}

The health care triangle is a common tool to describe the basic features of the health care system.

Figure 1: The health care triangle

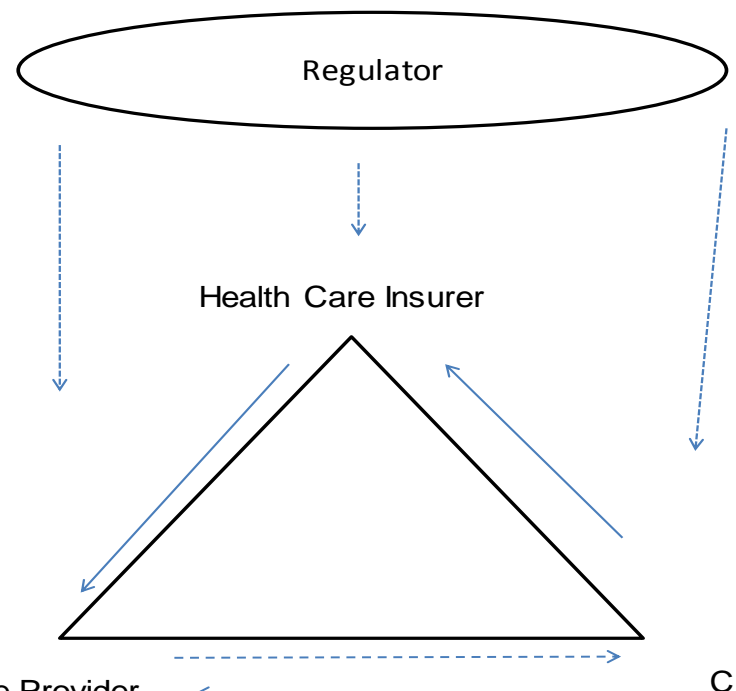

Health Care Provider

Citizen/Patient

In figure 1, the solid lines represent financial flows and the dashed lines represent service flows. There are three agents and three relationships. The population pre-pays for health services as citizens and receives and pays for services as patients. The pre-payment is in terms of insurance premiums or tax payment. The health care provider delivers services to the patients and receives revenue from the health care insurer and from the patient. Regulators, who have been delegated decision-making power from elected politicians, 
decide and supervise the constraints that agents operate under. In Figure 1, laws and regulations are shown by dotted lines.

In the Nordic systems, health insurance and health care are provided as a tax financed health service by the public sector at the central or decentralized level (disregarding private supplementary insurance). Financial flows from patient to health care provider are in terms of co-payments determined at national level or more decentralized, as in Sweden. The types and magnitudes of financial flows from insurer to provider are decided by the public insurer, either centralized or decentralized.

The term "health care provider" in Figure 1 covers health care providers both at the level of primary health care and at the level of specialized health care. For a patient with a minor acute health problem or a need of a follow-up, it is often sufficient to visit a GP. A patient with a major acute trauma may first be admitted to a university hospital. After being discharged, the patient may be under temporary surveillance by the local hospital before the GP takes over.

A patient with one or several chronic diseases, on the other hand, needs surveillance and treatment from many types of providers and may experience irregular hospital admissions if some acute condition develops. Hence, patients with chronic diseases require coordination between many types of providers in order for their treatment to be successful.

Coordination in chronic care is sometimes referred to as integrated health care or disease management (not to be confused with integrated health care system). Irrespective of the concept used, the mutual objective is to provide better care for the chronically ill. Nolte and McKee (2008) explain the notion of integration as "a range of approaches that are deployed to increase coordination, cooperation, continuity, collaboration and networking across different components of health service delivery".

To implement coordination mechanisms and facilitate systematic assessment of the mechanisms used for improving coordination, some type of taxonomy is useful. One example of such taxonomy refers to the degree of integration where a continuum of seven types of provision from a strict solo provision to a full integration of disciplines is defined (Boon et al., 2004). Nolte and McKee provide a detailed discussion of taxonomies of integration, covering type, breadth, degree and process of integration. As an example, organizational integration is one type of integration and relates to the creation of networks and contracting between healthcare institutions, while structural integration (an example of process of integration) refers to the alignment of tasks and activities of organizations and healthcare professionals.

The coordination mechanisms to which we relate our description of the Nordic health care sectors can be thought of as falling into the following overall categories (not mutually exclusive):

1. Direct regulation at the system level

2. Markets in a broad sense (including co-payments and financial incentives to providers)

3. Networks including professional norms

4. Organization/hierarchies.

The Nordic health systems are decentralized to various degrees (Lyttkens et al, in this issue). A description of coordination would then also need to contain a description of whether a set of coordination mechanisms applies to the entire system or only a part of it.

Several mechanisms may well supplement each other in a particular coordination. Hence, components are not exclusive. Consider patient access to specialist care. In some countries, the role of being a gatekeeper to specialist care is imposed on the GP. In other 
countries, GPs may not have a role as a formal gate-keeper, but patient co-payment and providers' financial incentives may pull decisions in a similar direction. Furthermore, rationing may be supported by both professional norms and explicit prioritization.

Sometimes mechanisms may even be conflicting. As a general example, efforts to standardize the work process may go against professionals demand for autonomy. Another, more specific example can be taken from Norway, where, the financial incentives that are created by paying hospitals a fee per treatment sometimes contradict decisions prescribed by the explicit prioritization regulation.

In Nolte and McKee's extensive review of integration in chronic care, they stress the importance of the uniqueness of every health care system when implementing mechanisms to improve coordination (2008). As an example, it cannot be assumed a priori that a coordination model delivering good outcomes in one health care system would also provide good outcomes if implemented in a different health care system. Therefore, it is important to explore the type, degree, breadth and process of coordination within each system before implementing mechanisms that are aimed at improving outcomes in chronic care.

\section{Description of some coordination mechanisms in the Nordic countries}

\subsection{Coordination of hospital structure in terms of assigning tasks to hospitals}

The size of a hospital catchment area is supposed to take into account increasing return to scale. Complicated treatments delivered to a relatively small number of patients may then be concentrated to a few hospitals. In all Nordic countries, there is a hierarchy of hospitals from local community hospitals to university hospitals. University hospitals often perform both common treatments and advanced treatments. Mechanisms that are used to coordinate hospital structure in terms of assigning tasks and treatments to hospitals become important, as the assignments have implications for patient services and the efficiency of the system. Often competing objectives are involved. For instance, an optimal composition of hospital volumes from a treatment quality perspective may not be in accordance with reasonable emergency care accessibility for the population living in remote areas.

In Denmark, almost all hospitals are owned and run by each of the five regions. However, in accordance with the Danish health law, the coordination of tasks to hospitals is regulated by the Danish Health and Medicines Agency (DHMA; in Danish: Sundhedsstyrelsen), which is the supreme health authority in Denmark. The DHMA specifies the requirements for hospital functions and approves the location of specialist functions and tasks (Sundhedsstyrelsen, 2015). For this purpose, the DHMA distinguishes between two overall types of tasks: general tasks and special functions. The latter is based on an assessment of the size of the patient group that is the target for the task and the complexity of the task and resource use for carrying out the task. Main tasks (approximately 90\% of all hospital treatment) can be carried out principally at any hospital. However, the regional health authorities are required to consult the DHMA for guidance regarding the allocation of tasks. Specialist functions are divided into three categories: first, hospital tasks that can be carried out in 1-3 hospitals in the region (regional functions); second, highly specialized functions that can be carried out in 1-3 hospitals in the country; and third, functions that are under development. In addition to these three specialist functions, very complex tasks that require high resource use and rarely are carried out are classified as specialized treatment abroad.

In Finland, the hospital structure is mainly based on independent decisions made by the 21 hospital districts. They make, for example, all decisions regarding investments in buildings and equipment. However, the Ministry regulates by means of government decrees 
the centralization of certain treatments. Some treatments have been centralized to five university hospitals. Certain treatments are even centralized to a specific university hospital. In addition, the Ministry can determine the quality standards that the service provider must meet and other requirements aimed at ensuring the appropriateness of the treatment provided. A recent example of this is a new decree defining the minimum annual volume for births (1000) for a hospital that can provide the services at issue.

In Iceland, the Ministry of Health is responsible for decisions and management regarding hospitals. This responsibility includes all investments in buildings and equipment. The Ministry is also responsible for coordination between institutions. Due to the small population, the most specialized surgeries are only conducted at Landspítali University Hospital (LUH). The ministry determines which treatments are to be given in other hospitals and health centers. In October 2014, the Ministry completed an agenda of mergers of health institutions outside of the capital region. Decision-making will be moved to a greater degree from the ministry to the local managers (decentralization at the managing level). This change does not entail a shift of financial responsibility away from the state to other levels of governance (Ministry of Health, 2015).

In Norway, there is a hierarchical hospital structure with four regional health authorities under the Ministry of Health and Care Services. The regional health authorities are owners of the hospitals within their regions and are responsible for investments and construction of new hospitals. As the minister of health is the general assembly of all four regional health authorities, the system is centralized in the sense that the minister of health has the authority to overrule all structural decisions that have been made at a lower level in the decision hierarchy. Although these decisions often are controversial at the local level, the decision-making authority at the central level probably implies more weight to cost and quality of specialized care at the society level.

In Sweden, coordination of tertiary care (among university hospitals) in six medical regions has been long established. Beginning in the mid-1990s, a restructuring of the role of hospitals, at all levels, has occurred. Most decisions have been made at the county council level. At the regional level, mergers between university-hospitals in Stockholm (Karolinska), Gothenburg (Sahlgrenska) and Malmö/Lund (Skåne) have been much debated and created significant tensions at clinical levels. Trauma care has been concentrated in larger hospitals. One reason for this development is that it is expensive to have on-call doctors in several areas. Another reason is a lack of relevant human resources and a concentration on improving quality. The restructuring of hospitals means that larger hospitals receive more acute cases. Smaller hospitals have seen a reduced role as 24-7 acutecare hospitals, and some are oriented towards planned surgery (e.g., hip and knee replacement) and care for the elderly. There have been national initiatives to set up national centers for highly specialized services (e.g., transplantation, children's heart surgery, and cancer care) and to set up six regional cancer centers with government support. The process towards concentration is slow because local hospitals often struggle to maintain services such as surgery.

\subsection{Gate-keeping versus financial incentives as coordination mechanisms that steer patient flows between primary care and specialized care}

Many countries have introduced restrictions on patients' access to specialized health care. A primary motivation is that sorting of patients by GPs may be beneficial to patients because of GPs' extensive knowledge of patient health. Another motivation is cost reduction at the system level because of reduced utilization of expensive specialized care. Furthermore, gatekeeping is associated with a more equitable distribution of specialized care in some 
countries (Devaux, 2015). Gatekeeping is controversial, both because of the direct rationing of access to specialized health care that is involved and the limited evidence available about the existing efficiency effect, as reviewed by Jelovac (2014).

Among the Nordic countries, Denmark and Norway have imposed gate-keeping on visits to specialized health care for patients in the list patient system. This policy means that a referral from a patient's regular GP is necessary in order for a patient to access specialized health care. There is also gate-keeping in Finland. Except for emergency cases, a patient is expected to have a referral from a doctor (from a health center, the private sector or occupational care) for public outpatient and inpatient hospital care. In Finland, it should be noted that private sector services and occupational care (depending on the content of contract with employer) also provide some specialist services. In Iceland, there is no gatekeeping, and the state does not have control of the use of private specialized care. Patients have the freedom to seek services directly from specialists who are reimbursed within a feefor service payment scheme. A fee to be paid for each consultation and other services is fixed by regulations and includes financial incentives at the level of the provider. In Sweden, there is generally no gate-keeping, and several different systems exist at the regional level to control the utilization of specialized services. In the Skåne region, as in several other county councils, the primary care centers have a financial responsibility for their patients' pharmaceutical expenditures and visit to other primary care centers and diagnostic procedures that are included in their primary care contracts (Anell, 2014). Through a reduced capitation they are also indirectly financially penalized for visits to specialized care. In addition, patients in all Swedish county councils have to pay a higher co-payment if they visit a specialist without a referral. Hence, there are financial incentives for patients to use primary care as their first level of service.

\subsection{Coordination of the diagnostics and treatment of cancer}

Diagnostics and treatment of cancer typically require services from many providers. Proper coordination between the providers is crucial for health outcomes. This section introduces coordination of cancer care by means of integrated care pathways.

Integrated care pathways that were introduced in Denmark in the autumn of 2007 have become an inspiration and model for several of the other countries. The motivation for the introduction of pathways in Denmark was a strong urge to improve the quality of cancer care. Such a pathway is a standard process in which all individual events, such as examinations and treatments, are specifically organized according to a pre-defined and prebooked process, both in terms of time and content. It covers the entire process starting from when a reasonable suspicion of cancer is realized through diagnosis, treatment and rehabilitation. That is, each event is subject to specific terms with fixed requirements for the timing of each event, the time between events and the content of these events (National Board of Health, 2015a).

The integrated care pathways aim to reduce processing times, including the time from referral, usually from a general practitioner, to the initiation of diagnosis at a hospital department and the onset of treatment. Furthermore, the integrated cancer pathways aim to ensure that clinical guidelines are implemented and that all cancer patients are treated in accordance to these guidelines (National Board of Health, 2015a).

In addition to describing all necessary tests, examinations and treatments that should be carried out, integrated care pathways also specify how health professionals must supply information to the individual patients and describe a number of outcome measures in order to monitor whether diagnosing and treatment comply with the integrated care pathway (National Board of Health, 2015a). 
The clinical content in each pathway is developed by a group of health professionals that represent all hospitals in the country.

At the time of writing, a total of 32 integrated cancer care pathways have been implemented in the Danish health care system (Statens Serum Institut, 2015).

The performance of the hospitals with regard to the integrated care pathways is centrally monitored. It is mandatory for each hospital to deliver patient specific data to Sundhedsdatastyrelsen, which is responsible for health surveillance and administering the national health databases. The data are included in the National Patient Register. Based on these data, Sundhedsdatastyrelsen publishes statistics on a quarterly basis in accordance with a monitoring model. Figure 2 below shows the monitoring model for the integrated cancer pathways. These statistics are available at www.esundhed.dk. Furthermore, the monitoring information system on cancer is used for benchmarking and statistical process control purposes for the clinical, hospital and regional management (National Board of Health, 2015).

\section{Figure 2: The monitoring model for integrated cancer pathways}

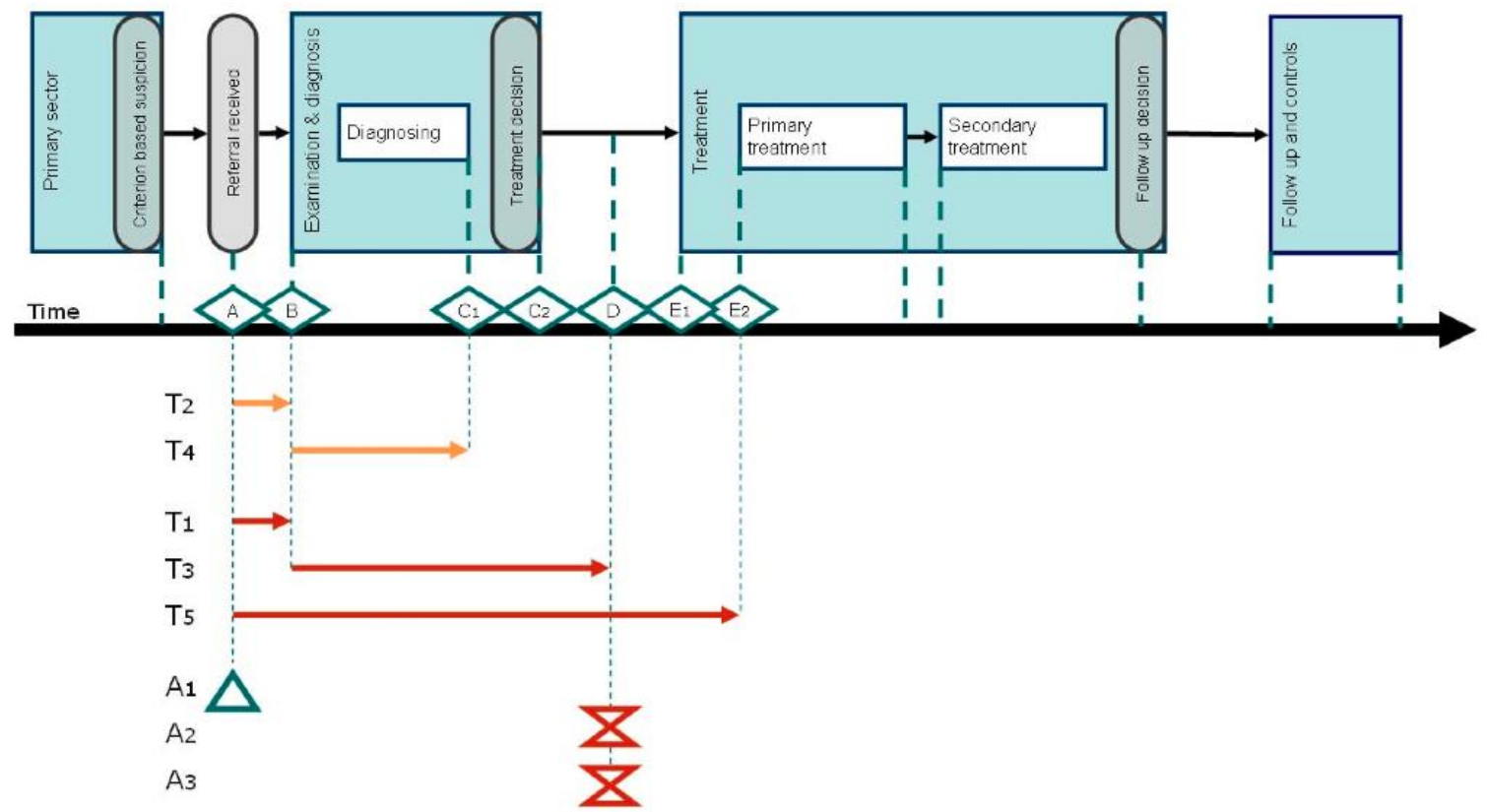

\section{Fixed Monitoring Points}

A Referral received

B Diagnostics start

$\mathrm{C}_{1} \quad$ Diagnosis disconfirmed

$\mathrm{C}_{2}$ Decision to treat

D Informed consent

$E_{1} \quad$ Treatment start, organizational

$\mathrm{E}_{2}$ Treatment start, clinical
Time and Activity Indicators

$\mathrm{T}_{1}$ Referral-period with cancer

$\mathrm{T}_{2}$ Referral-period without cancer

$\mathrm{T}_{3} \quad$ Examination-period with cancer

$\mathrm{T}_{4} \quad$ Examination-period without cancer

$\mathrm{T}_{5} \quad$ Period to treatment start

$A_{1} \quad$ Number of clinical pathways

$A_{2} \quad$ Share of pathways with cancer

$A_{3}$ Share of cancer in pathways

Source: The National Board of Health (2015b). Printed with permission from The National Board of Health. 
In Finland, pathways for cancer patients are under the responsibility of municipalities and hospital districts. This circumstance may suggest that there are great regional differences in patients' pathways and waiting times (Mäklin and Mäkelä, 2008), although no real life data are available. There are approximately 10 national guidelines for the treatment of different types of cancer, but these usually do not include recommendations regarding patient pathways. Some hospital districts have guidelines regarding the roles of different sectors (primary care, hospital care) in the treatment of breast cancer patients. A recent working group drew up proposals for intensifying and improving cancer treatments and defined the bodies responsible for their implementation. So far, the proposals have not been implemented (Sosiaali- ja terveysministeriö, 2010).

There is no direct regulation of the pathway for cancer patients in Iceland. The division of tasks within the specialized health care provision (specialized hospitals) is structured around multidisciplinary tumor boards. At LUH, a multidisciplinary tumor board - a team that is composed of a medical oncologist, a surgical oncologist, a radiation oncologist and a pathologist - meets weekly to gather information on patients who have been diagnosed with cancer and develop a treatment plan. The Ministry of Health is in the process of developing a cancer plan for Iceland.

In Norway, integrated care pathways based on the Danish model were introduced from 2015. Guidelines for 28 types of cancers have been implemented so far. Each pathway contains a systematic description of the stages and types of diagnostics and treatments and the maximum waiting times between the stages. Guidelines that inform the GPs about symptoms that qualify for a referral to an integrated care pathway are established. Each hospital department has a coordinator with whom patients and their GPs contact and who is responsible for making the reservations that are included in the pathway.

In Sweden, six regional cancer centers (RCC) were established in 2010. The six regions have somewhat different agendas and work in different ways although a national guidance of ten criteria was established when initiated. There is also coordination at national level regarding sharing of experiences, the (national) concentration of services, quality registers and more (www.cancercentrum.se). Several RCC has developed standardized pathways of their own. In 2014, however, a model of national standardized pathways, following experiences in Denmark, was initiated for five pilot cancer diagnoses. During 2015, these pathways were implemented and at least ten more pathways were developed during 2015 to be implemented in 2016.

\subsection{Coordination mechanisms for patients type 2 diabetes}

Chronic disease requires lifelong surveillance and treatment from several types and levels of providers. The coordination of services to patients with chronic diseases is a major issue in all health care systems. Nolte and McKee (2008) and Busse et al. (2010) elaborate on the health system challenges of chronic disease and the requirements for coordination and integration of health care. In particular, as a health care system becomes more coordinated and less fragmented, the outcomes in chronic care (where inputs are required from many professionals at different levels of delivery) are expected to be of better quality.

Generally, the coordination of common chronic diseases (like diabetes but also asthma/ chronic obstructive pulmonary disease (COPD)) is different in Finland and Sweden (taken care of by specialist nurses in primary care more or less) compared to Denmark and Norway (more physician involvement). The differences are probably linked in part to financial incentives (GPs are paid fees for providing care to patients with chronic diseases in Denmark and Norway) and in part to differences in the standardization of work and 
professional norms in the two groups of countries. In both Denmark and Norway, there are discussions of introducing more primary care teams inspired partly by Swedish experiences.

Below, we provide a brief description of the status of the coordination of care for patients with type 2 diabetes (T2DM) - an increasingly common chronic disease in the Nordic countries.

In Denmark, regional care pathways for T2DM have been developed or are under development. Additionally, national guidelines for the treatment of T2DM have been published recently (Sundhedsstyrelsen, 2015).

In Finland, the responsibility for coordination of care for patients with diabetes is given to hospital districts and municipalities. The main providers of services to diabetes patients are health centers and occupational care units. Some hospital districts have developed guidelines for the care of diabetes, and the newest national guideline was published in September 2013. Vehko et al. (2013) suggest that care pathways in diabetes care are relatively widely used and consistently defined in terms of professional skill-mix in Finland.

There are three providers of health care for diabetes in Iceland, of which patients have a free choice of where to seek service: An endocrinology outpatient unit at LUH, the primary care health centers (GPs) and specialists private practices. No formal integration exists between the aforementioned providers. Clinical guidelines published by the Directorate of health for T2DM in October 2009 do not include a care pathway as suggested in chronic care management or disease management programs. With a lack of registration at national level, it is not possible to collect overall quality indicators for the treatment of diabetes.

In Norway, clinical guidelines for the treatment T2DM were developed in 2009. An update is expected during 2016. There are some indications of variation of care depending on whether primary care or specialized care takes responsibility. There is no particular program for integration of care between the two levels of care. There is no systematic evaluation of whether or not the care that patients receive is in accordance with the guidelines.

In Sweden, national guidelines for treatments and a national quality register (NDR) exist, but coordination is determined regionally. For T2DM, the specialist diabetic nurses at primary care centers have an important role to support patients when following up and evaluating care. Patients with a diagnosis and stable treatment usually meet their GP once a year and when required during the year as suggested by the diabetic nurse and patient.

\subsection{Coordination of long term care and hospitals}

Patients in need of long-term care (LTC), such as a considerable proportion of the elderly population, will often have several chronic diseases and experience both planned and acute hospital admissions. With insufficient capacity in long-term care, a patient may experience excessive hospital stays, which in turn extends the delay for other patients who are waiting to be admitted to a hospital (bed-blocking). Hence, coordination between hospital and longterm care capacity is crucial to the efficient utilization of resources in the entire system.

In Denmark, home-based care and nursing home care are provided by the municipalities. According to the Consolidation Act on Social Services (in Danish: Serviceloven), the municipality "shall provide accommodation in facilities suitable for longterm accommodation for persons who, due to substantial and permanent impairment of physical or mental function, need extensive assistance for general day-to-day functions or care, attendance or treatment, where such needs cannot be addressed in any other way" 
(Ministry of Social Affairs and the Interior, 2016, §108), whereas nursing care is regulated by the Health Care Act (in Danish: Sundhedsloven).

Rehabilitation after discharge from a hospital is also the responsibility of the municipality. The individual region and the municipality in the region are required to enter into an agreement about the coordination of the treatment of their patients. The agreement must be approved by DHMA.

In addition, DHMA has prepared or is in the process of preparing a number of patient pathways for rehabilitation, e.g., for patients with COPD or acquired brain injury and stroke.

In Finland, long-term care homes (nursing homes), home services and primary care (including inpatient departments of health centers) are the responsibility of the municipalities, whereas acute care is provided by hospital districts. Because the final decision-making authority is given to municipalities, there exists much regional variation in how these services are organized. Currently in two areas (Kainuu and Eksote), the municipalities have given the responsibility to provide all health and social services (including LTC) to an upper-level organization (federation of municipalities). Conversely, some small municipalities (representing only a marginal share of population of the country) have outsourced all health and social services to private companies. We can expect that there are huge regional differences in patient pathways between hospital care and other services among the elderly populations. There are no national guidelines for coordination, but some hospital districts have developed guidelines for geriatric patents that include the duties of different sectors in the treatment of those patients.

Long-term care homes (nursing homes) in Iceland are financed by the government on fixed-budget items, as are hospitals and health centers. Social services related to homebased care (homemaker services) are, however, the financial responsibility of the municipalities. The state finances and manages in-patient rehabilitation units at hospitals and health institutions. In-patient rehabilitation outside of hospitals and health institutions are managed by non-profit organizations through service contracts with the Icelandic Health Insurance. Some nursing homes receive medical care services from Landspitali University Hospital (LUH).

In Norway, LTC and hospital care are organized at different levels of government. While financing and provision of LTC are the responsibilities of the municipalities, financing and the provision of hospital care are the responsibility of the state. The responsibility for rehabilitation is split between the two levels of government. According to regulations implemented as part of the coordination reform from 2012, hospitals and municipalities are obliged to have explicit cooperation contracts. Additionally, the municipalities are obliged to provide acute care beds from 2016, and there is a fine for hospital patients who are declared ready to be discharged by the hospital.

In Sweden, nursing home care and home care are the responsibility of the 290 municipalities. Collaboration with primary care services is needed, as municipalities are not allowed to employ physicians. For this purpose, nursing homes generally have agreements with health centers. In relation to hospital care, discharge planning for the elderly in collaboration with municipality and primary care is mandatory. The municipality is required by law to organize an adequate capacity of nursing home services. Problems of so-called bed-blockers have been discussed for decades, with municipalities having to pay a fine for patients declared ready to be discharged from a hospital since the so called ÄDEL reform in 1992. Regulation has been strengthened several times since then, and studies suggest that the problem of so-called bed-blockers has been reduced due to these policies. However, after each change, problems related to bed-blockers have reached a new plateau and is still debated as a significant problem both for the elderly and to improve the efficiency of hospitals. 


\section{A summary of the coordination mechanisms}

The description in Section 3 reveals variation in coordination mechanisms both between countries and areas according to the taxonomy introduced in Section 2. Direct regulation is the mechanism used for coordination of the hospital structure in all countries. In Finland and Sweden, there is less national coordination of the hospital structure compared with the other countries. In Iceland, there is less coordination between primary care and specialist care than in the other countries. In Sweden, there is relatively more reliance on financial incentives in the coordination between primary care and specialist care compared with Denmark and Norway, where direct regulation is more prevalent. Finland seems to rely on a mix of the coordination categories mentioned in Section 2. Diagnostics and treatment of cancer are major health policy issues in the five countries. Until recently, the main coordination mechanisms have been networks involving medical norms and some regulation in terms of, for instance, maximum waiting time in some countries. The introduction of integrated cancer care pathways in Denmark, Norway and Sweden means that coordination increasingly occurs by central regulations with financial punishment if standards are violated.

In terms of coordination of care to patients with chronic diseases, the picture is mixed. Several countries have guidelines that can perhaps be interpreted as a weak (less precise) form of care pathways. In Finland and Sweden, guidelines exist more at the regional level than in the other countries. No country seems to have systems for the evaluation of whether or not guidelines are adhered to. Hence, guidelines work more though professional networks than through regulations.

The coordination between hospital care and long term care is an important challenge in all five countries. At the general level, coordination is determined by direct regulations that are perhaps less operational in day-to-day operations. In Denmark, Norway and Sweden, hospital care and LTC are provided by different levels of government. There are mandatory agreements of coordination between the state/regions and municipalities. Recently, Norway has introduced financial incentives to prevent bed-blocking. This policy has been in place in Sweden in different forms since 1992.

The overall pattern shows that Finland and Sweden have less country-wide coordination compared with the other countries. This difference between the countries stems from the more decentralized ownership of hospitals in Finland and Sweden than in the other countries. There is also slightly more use of financial incentives in Sweden than in the other countries.

\section{Pros and cons of the coordination mechanisms as described in the international research literature}

An important question is whether some types of coordination mechanisms are more appropriate than others for achieving main goals of a public health care system, such as total health benefits, the equitable distribution of health benefits and the low-cost provision of health benefits. Research on which to make a judgment on this question is limited.

Mason et al. (2014, 2015) systematically review empirical studies of financial incentives that promote coordination and integrated care. Thirty-eight schemes, reported in 122 articles, meet their inclusion criteria. The costs and effects of the schemes, including unintended consequences, are described. They find that, compared with "usual care", schemes that integrate funds and resources to support integrated care seldom lead to improved health outcomes. No scheme demonstrates a sustained and long-term reduction in hospital use. Among the reported studies, there are two concerning Sweden. Hultberg et al. (2003) report from a study of pooled funding in the treatment of patients with 
musculoskeletal disorder. Few health effects and effects on resource use have been found. Øvretveit et al. (2011) report an empirical longitudinal study of the development of an integrated health and social care organization in Sweden. The study design was not able to establish whether better patient and cost outcomes resulted.

Additionally, studies of chronic care models reveal mixed results. Nolte and McKee (2008) conclude that findings from studies on the effectiveness of chronic care models are sensitive to how strong the primary care orientation is within a particular health system. That is, mechanisms to improve outcomes of chronic care are most likely to succeed in systems where patients are registered with a particular primary care facility that acts as a gatekeeper to secondary care. Busse et al. (2010) review mixed evidence on the effectiveness of gatekeeping and note that it is subject to factors such as how clearly defined the role of the GP is and possible conflicts rooted in the traditional hierarchy of the medical professions that might work against gatekeeping models. Furthermore, pay incentives are important to ensure involvement of professional groups in coordination models (Steuten et al. 2002; Schiötz, Frölich and Krasnik 2008 (in Busse et al.)) Apart from these effectiveness measures, it should also be noted that patient perception of the quality of care has been found to be positively related to the level of coordination within the health care service (Preston et al 1999).

Armitage et al. (2009) perform a systematic literature review of integrated care. They find a lack of high-quality, empirical studies providing evidence on how integrated health systems can improve service delivery and population health. The review also reveals a lack of standardized, validated tools that have been systematically used to evaluate integration outcomes. According to the authors, this makes measuring and comparing the impact of integration at the system, provider and patient levels challenging.

Huntley et al. (2013) systematically review evidence from randomized controlled trials regarding the effectiveness of case management in reducing the risk of unplanned hospital admissions in older people. Eleven trials of case management in the older population are included. Three trials report reduced lengths of stay. Eleven trials show no reduction of unplanned hospital admissions with case management compared with usual care.

Wadmann et al. (2009) describe and discuss the policy initiatives to improve collaboration between primary and secondary healthcare in Denmark and Sweden. They conclude that in both countries, economic incentives for collaboration are weak or lacking, and the use of sanctions as a regulatory means is limited. It is worth mentioning that several changes in regulation and incentives have occurred since this article was written.

Osborn et al. (2014) present the results of a computer-assisted telephone survey of the health and care experiences among 15,617 adults age 65 or older in Australia, Canada, France, Germany, the Netherlands, New Zealand, Norway, Sweden, Switzerland, the United Kingdom, and the United States. Norway and Sweden score quite poorly with regard to coordination of care experienced by patients. Among the Norwegians, $70 \%$ reported that they had experienced gaps in hospital discharge planning in the past two years. The corresponding figure for Sweden was $67 \%$.

From Norway, there are some studies of coordination mechanisms between hospital care and long-term care. Holmås et al. (2010) analyze the effect of fining owners of longterm care institutions who prolong lengths of stay at hospitals. They find that hospital lengths of stay are longer in the hospitals using fines to reduce lengths of stay compared with the hospital not using monetary punishment. They interpret the results as examples of monetary incentives crowding-out agents' intrinsic motivation. Holmås et al. (2013) find that bed-blocking costs due to missing coordination between hospital and care services constitute a relatively large share of the total costs of inpatient care. The ongoing evaluation 
of the coordination reform in Norway described in Section 3 is likely to contribute more knowledge about the possible gains from improved coordination between hospital care and LTC.

\section{Research ideas and concluding remarks}

Section 2 outlined that coordination exists at many different levels and in many different forms. Section 3 described the similarities and differences in coordination mechanisms among the Nordic countries. In some respects, we see that the Nordic countries approach coordination problems in similar ways (e.g., more national regulation and guidelines), although differences exist. The brief review in Section 5 revealed that there are many questions and few answers with regard to which mechanisms work best. Hence, coordination mechanisms in health care seem to be an important area for further research. A problem with national studies is often the difficulty of establishing exogenous variation in the institutional variables within a country. With data from several of the Nordic countries, it seems easier to establish both treatment and control countries among countries where some fundamental features are stable across countries. Below, we present some research ideas that will be considered by the group in the future.

Variation across countries with regard to the introduction of integrated cancer pathways could prove useful in studying whether the implementation of the pathways has influenced use of resources, equity, patient satisfaction and even cancer mortality, for instance, by means of difference-in-differences regression analyses.

Section 3 also revealed differences in treatment guidelines across countries. By exploiting the variation in the content and introduction of treatment guidelines, the effects of treatment guidelines on process and outcome measures could be studied.

The mechanisms for coordinating primary care and specialized care differ among the Nordic countries with more reliance on financial incentives in Sweden compared with the other countries and little coordination in Iceland. Recent changes in several counties of Sweden and more stable features in the other countries can motivate studies of the effect of financial incentives on the coordination of care.

Additionally, other more process-based outcome measures would be interesting to study further, such as whether attempts to coordinate primary care, hospital care and nursing home care for the elderly has the potential to reduce avoidable hospital services (hospitalization and acute visits).

Section 3 revealed variation across countries in the coordination of hospital structure in terms of assigning tasks to hospitals. This variation might be exploited in future studies of coordination mechanisms.

\section{Acknowledgements}

Financial support from the Nordic Research Council (project grant no: 229987/F10) is gratefully acknowledged. The authors would like to thank Carl Hampus Lyttkens, Terkel Christiansen and an anonymous referee for comments and suggestions to a previous version of the article. 


\section{References}

Anell, A. (2014). Jämförelse mellan almen praksis i Region Sjaelland och primärvård i Region Skåne. Skriftserie 2014:3. Institutet för ekonomisk forskning vid Lunds universitet, Lund.

Armitage, G. D., Suter, E., Oelke, N. D. and Adair, C. E. (2009). Health systems integration: state of the evidence. International Journal of Integrated Care, 9, 17 June 2009.

Boon $\mathrm{H}$ et al. (2004). From parallel practice to integrative health care: A conceptual framework. BMC Health Services Research, 4:15.

Busse, R., Blümel, M., Scheller-Kreinsen, D, and Zentner, A. (2010). Tackling chronic disease in Europe. Strategies, interventions and challenges. Observatory Studies Series No 20. European Observatory on Health, World Health Organization.

Devaux, M. (2015). Income-related inequalities and inequities in health care services utilization in 18 selected OECD countries. European Journal of Health Economics 16, 21-33.

Holmås, T. H., Kjerstad, E., Lurås, H. and Straume, O. R. (2010). Does monetary punishment crowd out pro-social motivation? A natural experiment on hospital length of stay. Journal of Economic Behavior \& Organization 75, 261-267.

Hultberg, E.L., Lonnroth, K., and Allebeck, P. (2003). Co-financing as a means to improve collaboration between primary health care, social insurance and social service in Sweden. A qualitative study of collaboration experiences among rehabilitation partners. Health Policy, 64, 143-52.

Huntley, A. L. et al. (2013). Is case management effective in reducing the risk of unplanned hospital admissions for older people? A systematic review and meta-analysis. Family Practice 30, 266275.

Jelovac, I. (2014). Primary Care, gatekeeping and incentives. In A.J. Culyer (ed): Encyclopedia of Health Economics Volume 3 (142-145). Amsterdam: Elsevier Science.

Mason, A., Goddard, M., and Weatherly, H. (2014). Financial mechanisms for integrating funds for health and social care: an evidence review. CHE Research Paper 97. Centre for Health Economics, University of York, UK.

Mason, A., Goddard, M., Weatherly, H., and Chalkley, M. (2014). Integrating funds for health and social care: an evidence review. Journal of Health Services Research \& Policy, 20, 177-188.

Mäklin S, Mäkelä M. Hoitoon pääsy syöpätaudeissa. (In Finnish: Access to treatment in cancer) Stakes työpapereita 22/2008 https://www.julkari.fi/bitstream/handle/10024/77660/T33-2008VERKKO.pdf?sequence $=1$

Ministry of Social Affairs and the Interior (2016). Consolidation Act on Social Services, Consolidation Act no. 1093 of 5 September 2013. Available 363/consolidation-act-on-socialservices.pdf (2nd March 2016)

Nolte, E., McKee, M., (eds). (2008). Caring for people with chronic conditions: A health system perspective. Open University Press, Berkshire, England.

National Board of Health (2015a). Integrated cancer pathways (In Danish: Pakkeforløb på kræftområdet). Available at http://sundhedsstyrelsen.dk/da/sundhed/folkesygdomme/kraeft/ pakkeforloeb (19th February 2015).

National Board of Health (2015b). Monitoring of Integrated Cancer Pathways. Available at $\mathrm{http} / / /$ sundhedsstyrelsen.dk/en/health/widespread-diseases/cancer/ /media/4857226F41A640 F68A4158DAD0B3D4ED.ashx (19th February 2015).

Osborn, R., Moulds, D., Squires, D., Doty, M. M., Anderson, C. (2014). International survey of older adults finds shortcomings in access, coordination, and patient-centered care. Health Affairs, 33, 2247-2255.

Preston, C. et al. (1999). Left in limbo: Patients' views on care across the primary/secondary interface. Quality in Health Care, 8:16-21. 
Smith PC, Anell A, Busse R, et al. (2012). Leadership and governance in seven developed health systems. Health Policy, 106(1), 37-49.

Sosiaali- ja terveysministeriö (2010). Syövän hoidon kehittäminen vuosina 2010-2020. (in Finnsh;Development of cancer treatment in 2010-2020, Working group report) Sosiaali- ja terveysministeriön selvityksiä 2010:6.http://www.stm.fi/julkaisut/nayta/-/_julkaisu/1486858

Statens Serum Institut (2015). Monitorering af pakkeforlфb på kraeftområdet (In Danish: Monitoring cancer pathways). Available at www.esundhed.dk/sundhedsaktivitet/kræftområdet/CAP1/ Sider/CAP1.aspx (19th February 2015).

Sundhedsstyrelsen (2015). National klinisk retningslinje for udvalgte sundhedsfaglige indsatser ved rehabilitering til patienter med type 2 diabetes. København: Sundhedsstyrelsen, juli 2015 (http://fysio.dk/Upload/Fafo/PDF/Kliniske\%20Retningslinjer/Diabetes/NKR_diabetes 2_2015.pdf - 8th September 2015).

The Ministry of Health (2015). Accessed $5^{\text {th }}$ of February, www.velferdarraduneyti.is/verkefni/ heilbrigdisthjonusta/

Wadmann, S., Strandberg-Larsen, M., and Vrangbæk, K. (2009). Coordination between primary and secondary healthcare in Denmark and Sweden. International Journal of Integrated Care Vol. 9, 12 March 2009.

Vehko T., Knai, C., Hawkesworth, S, McKee, M, Keskimäki , I. (2013).Care pathways in diabetes management in Finnish health care. The European Journal of Public Health, 23(1) (http:// eurpub.oxfordjournals.org/content/23/suppl_1/ckt123.007.full)

Øvretveit, J., Hansson, J., and Brommels, M., (2010). An integrated health and social care organisation in Sweden: creation and structure of a unique local public health and social care system. Health Policy 97, 113-21.

(C) 2016 by the author(s). This article is an open access article distributed under the terms and conditions of the Creative Commons Attribution license (http://creativecommons.org/licenses/by/4.0/). 